\title{
Effect of 3-hydroxybutyrate, an endogenous histone deacetylase inhibitor, on $F O X O 3 A$ mRNA expression in human epithelial colorectal Caco-2 cells: Insight into the epigenetic mechanisms of electric field therapy
}

\author{
Yuzo Nakagawa-Yagi ${ }^{* 1}$, Hiroyuki Hara ${ }^{1}$, Hidenori Tsuboi ${ }^{2}$, Junji Abe ${ }^{3}$ and Akikuni Hara ${ }^{1}$ \\ ${ }^{1}$ Hakuju Institute for Health Science Co., Ltd., 37-5 Tomigaya 1-chome, Shibuya-ku, Tokyo 151-0063, Japan \\ ${ }^{2}$ Acel, Inc., SIC-1 1201, 5-4-21 Nishihashimoto, Midori-ku, Sagamihara, Kanagawa 252-0131, Japan \\ ${ }^{3}$ Human Metabolome Technologies Inc., 246-2 Mizukami Kakuganji, Tsuruoka, Yamagata 997-0052, Japan
}

\begin{abstract}
3-Hydroxybutyrate (beta-hydroxybutyrate or 3-HBA) is small lipid-derived molecule that serves as an energy carrier during fasting, and endogenous inhibitor of histone deacetylase (HDAC). Here we report the concentrations of 3-HBA in plasma samples obtained from healthy human subjects before and after exposure to a single 30-min high-voltage electric potential (HELP) exposure using quantitative capillary electrophoresis-time-of-flight mass spectrometry (CE-TOFMS). 2 - and 3-HBA were significantly upregulated after HELP exposure (4.5 kV/electrode $+4.5 \mathrm{kV} / \mathrm{electrode})$, but not after exposure to low-strength condition (2.25 $\mathrm{kV} /$ electrode $+2.25 \mathrm{kV} /$ electrode). There was no effect on the concentrations of 2-hydroxybutanedioate, 2-hydroxytricarballylate, 2-oxopropanoate, or ATP. Because $3-\mathrm{HBA}$ is known to induce histone acetylation at the forkhead box O3a (FoxO3a) promoter, we further confirmed that $F O X O 3 A$ mRNA was upregulated by $3-\mathrm{HBA}$ treatment in a human epithelial colorectal adenocarcinoma Caco-2 cell line. Under these conditions stated above, 3-HBA treatment had no effect on forkhead box P3 (FOXP3) or defensin beta 132 (DEFB132) mRNA expressions. Similar changes in FOXO3A mRNA expression were obtained using sodium 4-phenylbutyrate (4-PBA) or trichostatin A (TSA) instead of 3-HBA. Our findings provide a new insight into the epigenetic mechanisms of electric field (EF) therapy.
\end{abstract}

\begin{abstract}
Abbreviations: ATP: adenosine triphosphate; CE-TOFMS: capillary electrophoresis-time-of-flight mass spectrometry; DEFB132: defensin beta 132; DMSO: dimethyl sulfoxide; EF: electric field; FOXO3A: forkhead box O3a; FOXP3: forkhead box P3; GPR: G protein-coupled receptor; 3-HBA: 3-hydroxybutyrate; HDAC: histone deacetylase; HELP: high-voltage electric potential; HMDB: human metabolome database; 4-PBA: sodium 4-phenylbutyrate; qRT-PCR: quantitative real-time polymerase chain reaction; TCA: tricarboxylic acid; and TSA: trichostatin A
\end{abstract}

\section{Introduction}

A therapeutic device to expose the human body to high-voltage electric potential (HELP) was approved by the Ministry of Health, Labour and Welfare in Japan [1-12]. High-voltage electric field (EF) therapy has been reported as an effective treatment for stiff shoulders, headaches, insomnia, and chronic constipation [1-9]. Key mediators, such as signaling metabolites and peptide hormones, have been suggested as candidate molecules that represent the interface between symptoms and electroceutical target proteins [10-12]. We previously demonstrated that among the 161 metabolites detected by non-targeted metabolomics, the most notable changes after HELP exposure $(9 \mathrm{kV} /$ electrode $+9 \mathrm{kV} /$ electrode, $30 \mathrm{~min}$ ) included several lipid-derived signaling molecules, such as the fatty acid amides oleoylethanolamide and palmitoylethanolamide [10]. Moreover, we determined that linoleic acid (18:2n-6)-derived hydroxyl-fatty acids, such as 9-hydroxyoctadecadienoic acid and 13-hydroxyoctadecadienoic acid are sensitive to a single HELP exposure $(9 \mathrm{kV} /$ electrode $+9 \mathrm{kV} /$ electrode, $30 \mathrm{~min}$ ) in healthy human subjects [12]. A recent study by Shimazu et al. reported that a lipid-derived molecule 3-HBA induces histone hyperacetylation in HEK293 cells [13]. 3-HBA is an endogenous dietary restriction (DR) mimetic molecule that extends the lifespan of Caenorhabditis elegans [14-15]. Considerable evidences of the lifespan extension elicited by epigenetic modifications, such as Jumonji domain-containing protein 2A histone demethylase, lysinespecific histone demethylase 1 (LSD1), and HDAC have been obtained from the study of DR mimetic compounds [16-22]. The observations of Shimazu et al. led us to study the effect of HELP exposure on quantitative concentrations of 3-HBA using a CE-TOFMS analysis [13]. Here we report that 3-HBA is upregulated by HELP exposure ( $4.5 \mathrm{kV} /$ electrode $+4.5 \mathrm{kV} /$ electrode, $30 \mathrm{~min})$. Because treatment with 3-HBA was reported to induce Foxo3a expression in mouse kidneys [13], we also investigated the effects of 3 -HBA on FOXO3A mRNA expression in a human epithelial colorectal adenocarcinoma Caco-2 cell line.

Correspondence to: Yuzo Nakagawa-Yagi, Ph.D, Office address: Hakuju Institute for Health Science Co., Ltd., 37-5 Tomigaya 1-chome, Shibuya-ku, Tokyo 1510063, Japan, Tel: (+81)3-5478-8833; Fax: (+81)3-5478-9821; E-mail: yagi@hakuju.co.jp

Key words: 3-hydroxybutyrate, HDAC inhibitor, FOXO3A, Caco-2 cells, electric field therapy

Received: August 31, 2016; Accepted: September 01, 2016; Published: September 13, 2016 


\section{Materials and methods}

\section{EF exposure}

The system used for EF exposure was previously described [1-12]. Briefly, the EF system was equipped with a transformer, a seat, and two insulator-covered electrodes. One electrode was placed on a floor plate with the subject's feet, whereas the other electrode was placed above the subject's head. EF generated by the HELP apparatus (Healthtron Hb9000T; Hakuju Institute for Health Science Co., Ltd., Tokyo, Japan) was uniformly created by transforming a $50-\mathrm{Hz}$ alternating current at $9 \mathrm{kV}$. The safety of this system for human use was established by the Japanese government in 1963.

\section{Subjects}

Ten healthy adults [ 6 males and 4 females; mean age, $44.4 \pm 3.1$ years; mean body mass index (BMI), $\left.22.3 \pm 1.0 \mathrm{~kg} / \mathrm{m}^{2}\right]$ participated in experiment 1 (exposure conditions: $4.5 \mathrm{kV}$ /electrode $+4.5 \mathrm{kV} /$ electrode, $30 \mathrm{~min})$. Ten healthy adults $(6$ males and 4 females; mean age, $43.4 \pm 3.6$ years; mean BMI, $24.3 \pm 1.3 \mathrm{~kg} / \mathrm{m}^{2}$ ) participated in experiment 2 (exposure conditions: $2.25 \mathrm{kV} /$ electrode $+2.25 \mathrm{kV} /$ electrode, $30 \mathrm{~min}$ ). All experiments were performed in the morning and all participants signed an informed consent form after receiving verbal and written information about the study. All experiments were conducted in accordance with the Declaration of Helsinki and the study protocol was approved by the human ethics committee of the Hakuju Institute for Health Science Co., Ltd. (Tokyo, Japan).

\section{Plasma preparation}

Blood samples were collected in vacutainer tubes coated with ethylenediaminetetraacetic acid (VP-NA070K; Terumo Corporation, Tokyo, Japan) and immediately centrifuged at $800 \times \mathrm{g}$ for $5 \mathrm{~min}$ to separate the plasma from other cellular materials. The plasma was then transferred to a fresh Eppendorf tube and stored at $-80^{\circ} \mathrm{C}$ until processing.

\section{CE-TOFMS measurement}

Metabolites were measured as previously described [10]. Briefly, $50 \mu \mathrm{L}$ of plasma was added to $450 \mu \mathrm{L}$ of methanol containing internal standards (Solution ID: H3304-1002; Human Metabolome Technologies, Tsuruoka, Japan) at $0^{\circ} \mathrm{C}$ to inactivate enzymes. The extract solution was thoroughly mixed with $500 \mu \mathrm{L}$ of chloroform and $200 \mu \mathrm{L}$ of Milli-Q water and centrifuged at 2,300 $\mathrm{x} g$ and $4^{\circ} \mathrm{C}$ for $5 \mathrm{~min}$. Next, $350 \mu \mathrm{L}$ of the upper aqueous layer was centrifugally filtered through a Millipore 5-kDa cut-off filter (Millipore Corporation, Billerica, MA, USA) to remove the proteins. The filtrate was centrifugally concentrated and re-suspended in $50 \mu \mathrm{L}$ of Milli-Q water for CEMS analysis. The systems were controlled using Agilent G2201AA ChemStation software version B.03.01 for CE (Agilent Technologies).

\section{LC-TOFMS measurement}

A $500 \mu \mathrm{L}$ aliquot of plasma was added to $1,500 \mu \mathrm{L}$ of a $1-\%$ formic acid/acetonitrile containing internal standard solution (Solution ID: H3304-1002, Human Metabolome Technologies) at $0^{\circ} \mathrm{C}$ to inactivate enzymes. The solution was thoroughly mixed and centrifuged at 2,300 $\mathrm{x} g$ and $4^{\circ} \mathrm{C}$ for $5 \mathrm{~min}$. The supernatant was filterted using a hybrid SPE phospholipid cartridge (55261-U; Supelco, Bellefonte, PA, USA) to remove phospholipids. The filtrate was desiccated and then dissolved in $100 \mu \mathrm{L}$ of isopropanol/Milli-Q water for LC-MS analysis. LC-TOFMS was performed using an Agilent LC System (Agilent 1200 series RRLC system SL) equipped with an Agilent 6230 TOF mass spectrometer (Agilent Technologies, Waldbronn, Germany). The systems were controlled using Agilent G2201AA ChemStation software version B.03.01 for CE (Agilent Technologies). Cationic and anionic compounds were measured using an octadecylsilane column $(2 \times 50 \mathrm{~mm}, 2 \mu \mathrm{M})$ [10]. The MasterHands automatic integration software (Keio University, Tsuruoka, Japan) was used to obtain peak information including the $\mathrm{m} / z$ ratio, retention time for LC-TOFMS measurement (RT), and peak area. Signal peaks corresponding to isotopomers, adduct ions, and other ions of known metabolites were excluded. The remaining peaks were annotated with putative metabolites from the HMT metabolite database based on MT/RT and $\mathrm{m} / \mathrm{z}$ values as determined by TOFMS. The tolerance range for the peak annotation was configured to $\pm 0.5 \mathrm{~min}$ for MT and $\pm 10 \mathrm{ppm}$ for $m / z$. In addition, peak areas were normalized against internal standards, and the resulting relative area values were further normalized by the sample amount.

\section{Quantitative real-time polymerase chain reaction (qRT-PCR)}

Human epithelial colorectal Caco-2 cells (RIKEN BRC, Tsukuba, Japan) were cultured in MEM medium (Nacalai Tesque, Kyoto, Japan) supplemented with $0.1 \mathrm{mM}$ NEAA (Thermo Fisher Scientific, Waltham, MA, USA), penicillin-streptomycin (Nacalai Tesque, Kyoto, Japan), and 20\% fetal bovine serum (Nichirei Biosciences, Tokyo, Japan). Briefly, $5 \times 10^{3}$ cells were seeded in type I collagen-coated 96well culture plates (Corning, NY, USA). After 4 days, the medium was changed to a fresh medium, containing sodium DL-3-hydroxybutyrate. qRT-PCR was performed as previously described $[10,18]$. Total RNA $(1 \mu \mathrm{g})$ was isolated from mycelia fragments using the RNeasy Plus Micro Kit (Qiagen, Valencia, CA, USA) and then reverse transcribed using the QuantiTect Reverse Transcription Kit (Qiagen, Valencia, CA, USA) with the following primers : FOXO3A-F, TCA ATC AGA ACT TGC TCC ACC A; FOXO3A-R, GGA CTC ACT CAA GCC CAT GTT G; FOXP3-F, GAA AAC AGC ACA TTC CCA GAG TTC; FOXP3-R, ATG GCC CAG CGG ATG AG; DEFB132-F, GGT GGG TCA AAA TGT GTG AGT; DEFB132-R, GCT GTG GTA GGT CAG GCT TC; GAPDH-F, CAT CCC TGC CTC TAC TGG CGC TGC C; and GAPDH-R; CCA GGA TGC CCT TGA GGG GGC CCT C. All qRT-PCR reactions were performed using the SYBR Premix EX Tag (Takara Bio Inc., Otsu, Japan). Amplification and detection were performed under the following conditions: $95^{\circ} \mathrm{C}(10 \mathrm{sec})$ and $60^{\circ} \mathrm{C}(30$ sec) for 40 cycles. Fold induction values were calculated according to the equation $2^{\Delta \Delta} \mathrm{Ct}$, which indicates the differences in cycle threshold numbers between the target gene and glyceraldehyde 3-phosphate dehydrogenase 2 (GAPDH2), $\triangle \Delta \mathrm{Ct}$ represents the relative differences between the control and treatment groups.

\section{Chemicals}

Sodium DL-3-hydroxybutyrate was purchased from Tokyo Chemical Industry (Tokyo, Japan). Sodium 4-phenylbutyrate was purchased from Sigma-Aldrich (St. Louis, MO, USA). Trichostatin A was purchased from Wako Pure Chemical (Osaka, Japan).

\section{Statistical analysis}

Data were analyzed using Welch's $t$-test. A $p$-value of $<0.05$ was considered statistically significant.

\section{Results}

Effect of HELP exposure on 3-HBA and related metabolite concentrations in the plasma of healthy humans

We assessed the 3-HBA in the plasma obtained from 10 healthy 
Nakagawa-Yagi Y (2016) Effect of 3-hydroxybutyrate, an endogenous histone deacetylase inhibitor, on FOXO3A mRNA expression in human epithelial colorectal Caco-2 cells: Insight into the epigenetic mechanisms of electric field therapy

participants using quantitative CE-TOFMS analysis. HELP exposure (4.5 kV/electrode $+4.5 \mathrm{kV} /$ electrode, $30 \mathrm{~min})$ produced significantly higher plasma concentrations of 3-HBA $(62.3 \pm 12.8 v s .38 .6 \pm 4.0 \mu \mathrm{M}$, $p=0.039)$ and 2 -HBA $(44.6 \pm 5.9 v s .34 .4 \pm 3.9 \mu \mathrm{M}, p=0.004)$ when compared with the pre-exposure levels (Table 1 and Figure 1). Under these conditions, HELP exposure $(4.5 \mathrm{kV} /$ electrode $+4.5 \mathrm{kV} /$ electrode, $30 \mathrm{~min}$ ) did not affect the concentrations of 2-hydroxybutanedioate, 2-hydroxytricarballylate, 2-oxopropanoate, or ATP (Table 1 and Figure 1). Furthermore, we investigated the effect of EF strength on 3-HBA and 2-HBA concentrations. A lower-strength HELP exposure $(2.25 \mathrm{kV} /$ electrode $+2.25 \mathrm{kV} /$ electrode, $30 \mathrm{~min}$ ) did not affect the concentrations of 3-HBA, 2-HBA, 2-hydroxybutanedioate, 2-hydroxytricarballylate, 2-oxopropanoate, or ATP (Table 1).

Changes in 3-HBA may have parallel increases in plasma fatty acid levels [14]; thus, we also examined the effect of HELP exposure for 30 min on fatty acids in the plasma obtained from 10 healthy participants using LC-TOFMS analysis. There was a remarkable difference in the level of fatty acids [palmitoleic acid, oleic acid, linoleic acid, $\mathrm{FA}(22: 5)$, linolenic acid, cis-4,7,10,13,16,19-docosahexaenoic acid, and cis- 8,11,14-eicosatrienoic acid] before and after HELP exposure (4.5 $\mathrm{kV} /$ electrode $+4.5 \mathrm{kV} /$ electrode) (Table 2). Under these conditions, HELP exposure had no effect on cis-5,8,11,14,17-eicosapentaenoic acid, arachidonic acid, or lauric acid (Table 2). A lower-strength HELP exposure $(2.25 \mathrm{kV} /$ electrode $+2.25 \mathrm{kV} /$ electrode $)$ had no effect on palmitoleic acid, oleic acid, linoleic acid, FA(22:5), linolenic acid, cis-4,7,10,13,16,19-docosahexaenoic acid, cis-5,8,11,14,17eicosapentaenoic acid, cis-8,11,14-eicosatrienoic acid, arachidonic acid, or lauric acid (Table 2).

\section{Effect of 3-HBA treatment on FOXO3A mRNA expression in a human epithelial colorectal adenocarcinoma Caco-2 cell line}

3-HBA is known to induce upregulation of oxidative stress resistance genes, such as FoxO3a, in mice [13]. Thus, we examined the effect of 3-HBA treatment on FOXO3A mRNA using qRT-PCR (Figure 2a). In a human epithelial colorectal adenocarcinoma Caco2 cell line, 3-HBA produced a dose-dependent increase in FOXO3A mRNA expression (3-HBA-2.4 mM: 1.42-fold, $p=0.063$; 3-HBA-9.6 $\mathrm{mM}$ : 1.68 -fold, $p=0.007)$.

Table 1. Effect of HELP exposure (30 min) on 3-HBA and related metabolites in the plasma of healthy humans.

\begin{tabular}{|c|c|c|c|c|c|}
\hline Metabolites $(\boldsymbol{\mu M})$ & & Before & After & Ratio & $p$ value \\
\hline & HMDB ID & Mean $\pm \mathrm{SE}$ & Mean $\pm \mathrm{SE}$ & After/Before & \\
\hline \multicolumn{6}{|c|}{$4.5 \mathrm{kV} /$ electrode $+4.5 \mathrm{kV} /$ electrode condition $(\mathrm{n}=10)$} \\
\hline 3-Hydroxybutyrate (3-HBA) & HMDB00357 & $38.6 \pm 4.0$ & $62.3 \pm 12.8$ & 1.61 & $0.039 *$ \\
\hline 2-Hydroxybutyrate (2-HBA) & HMDB00008 & $34.4 \pm 3.9$ & $44.6 \pm 5.9$ & 1.30 & $0.004 * *$ \\
\hline 2-Hydroxybutanedioate & HMDB00744 & $7.32 \pm 0.47$ & $6.61 \pm 0.59$ & 0.90 & 0.276 \\
\hline 2-Hydroxytricarballylate & HMDB00094 & $173 \pm 9$ & $171 \pm 9$ & 0.99 & 0.804 \\
\hline 2-Oxopropanoate & HMDB00243 & $120 \pm 8$ & $117 \pm 8$ & 0.97 & 0.639 \\
\hline ATP & HMDB00538 & $15.5 \pm 1.5$ & $12.2 \pm 1.8$ & 0.78 & 0.107 \\
\hline \multicolumn{6}{|c|}{$2.25 \mathrm{kV} /$ electrode $+2.25 \mathrm{kV} /$ electrode condition $(\mathrm{n}=10)$} \\
\hline 3-Hydroxybutyrate (3-HBA) & HMDB00357 & $41.8 \pm 4.4$ & $53.4 \pm 14.3$ & 1.28 & 0.429 \\
\hline 2-Hydroxybutyrate (2-HBA) & HMDB00008 & $35.6 \pm 3.4$ & $41.4 \pm 5.1$ & 1.16 & 0.063 \\
\hline 2-Hydroxybutanedioate & HMDB00744 & $7.63 \pm 0.57$ & $7.72 \pm 0.44$ & 1.01 & 0.882 \\
\hline 2-Hydroxytricarballylate & HMDB00094 & $189 \pm 9$ & $187 \pm 9$ & 0.99 & 0.753 \\
\hline 2-Oxopropanoate & HMDB00243 & $134 \pm 6$ & $135 \pm 9$ & 1.01 & 0.901 \\
\hline ATP & HMDB00538 & $10.3 \pm 1.5$ & $8.8 \pm 1.0$ & 0.85 & 0.328 \\
\hline
\end{tabular}

* Indicates a significant difference $(* p<0.05, * * p<0.01, t$-test $)$.
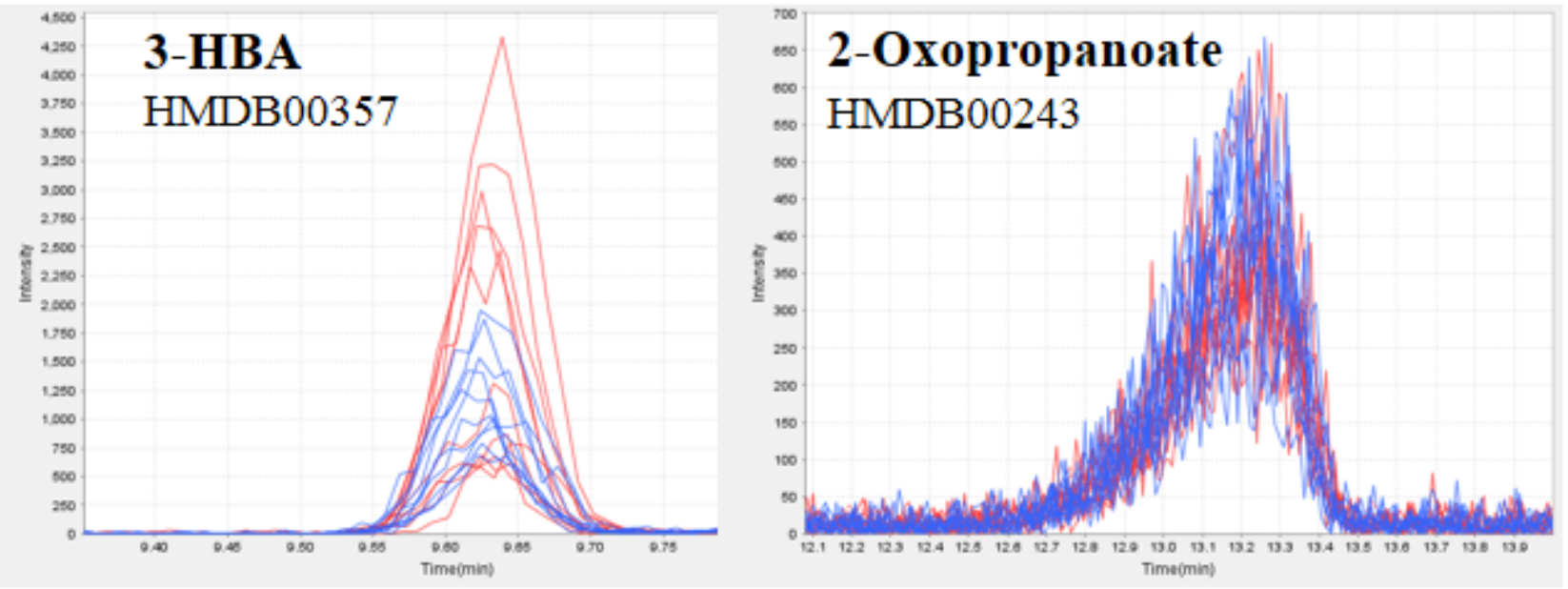

Figure 1. CE-TOFMS analysis of the plasma of healthy humans before and after HELP exposure for $30 \mathrm{~min}$.

Typical 3-HBA (a) or 2-oxopropanoate (b) peak in the plasma of healthy humans. 3-HBA and 2-oxopropanoate were detected by CE-TOFMS. The figure includes overlaid electropherograms of samples before (blue, $\mathrm{n}=10$ ) and after (red, $\mathrm{n}=10)$ treatment. 
To determine the specificity of 3-HBA for FOXO3A, we examined the effect of 3-HBA on FOXP3 or DEFB132 mRNA expressions. 3-HBA had no effect on FOXP3 or DEFB132 mRNA expressions in Caco-2 cells (Figure 2b-2c).

We also determined if well-known HDAC inhibitors, such as 4-PBA and TSA, mimicked the effect of 3-HBA in Caco-2 cells. As shown in Figure 2d, qRT-PCR showed an approximate 4.0-fold and 2.6-fold increase in $\mathrm{FOXO} 3 \mathrm{~A}$ mRNA expression after treatment with 4-PBA $(10 \mathrm{mM})$ and TSA $(3 \mu \mathrm{M})$, respectively.

\section{Discussion}

In this study, we showed that 2 -HBA and $3-\mathrm{HBA}$ are sensitive to a single exposure of $\mathrm{EF}$ ( $4.5 \mathrm{kV} /$ electrode $+4.5 \mathrm{kV} /$ electrode $)$ in healthy human subjects. However, 2-hydroxybutanedioate (malic acid; a marker metabolite of the TCA cycle), 2-hydroxytricarballylate (citric acid; a marker metabolite of the TCA cycle), 2-oxopropanoate (pyruvic acid; a marker metabolite of the glycolysis), and ATP (a

Table 2. Effect of HELP exposure ( $30 \mathrm{~min}$ ) on fatty acids in the plasma of healthy humans.

\begin{tabular}{|c|c|c|c|c|}
\hline \multirow[t]{2}{*}{ Fatty acids } & \multicolumn{2}{|c|}{$4.5 \mathrm{kV}+4.5 \mathrm{kV}$} & \multicolumn{2}{|c|}{$2.25 \mathrm{kV}+2.25 \mathrm{kV}$} \\
\hline & Ratio & $p$ value & Ratio & $p$ value \\
\hline & \multicolumn{2}{|c|}{$\mathrm{n}=10$} & \multicolumn{2}{|c|}{$\mathrm{n}=\mathbf{1 0}$} \\
\hline Palmitoleic acid & 2.07 & $0.012 *$ & 1.43 & 0.160 \\
\hline Oleic acid & 1.87 & $0.009^{* *}$ & 1.42 & 0.143 \\
\hline Linoleic acid & 1.83 & $0.013^{*}$ & 1.30 & 0.216 \\
\hline $\mathrm{FA}(22: 5)$ & 1.80 & $0.035^{*}$ & 1.46 & 0.133 \\
\hline Linolenic acid & 1.80 & $0.015^{*}$ & 1.29 & 0.310 \\
\hline $\begin{array}{l}\text { cis-4,7,10,13,16,19- } \\
\text { Docosahexaenoic acid }\end{array}$ & 1.63 & $0.041^{*}$ & 1.35 & 0.170 \\
\hline $\begin{array}{l}\text { cis-5,8,11,14,17- } \\
\text { Eicosapentaenoic acid }\end{array}$ & 1.55 & 0.092 & 1.30 & 0.197 \\
\hline cis-8,11,14-Eicosatrienoic acid & 1.55 & $0.032 *$ & 1.30 & 0.170 \\
\hline Arachidonic acid & 1.55 & 0.059 & 1.25 & 0.268 \\
\hline Lauric acid & 1.14 & 0.053 & 0.92 & 0.386 \\
\hline
\end{tabular}

* Indicates a significant difference $(* p<0.05, * * p<0.01, t$-test $)$.
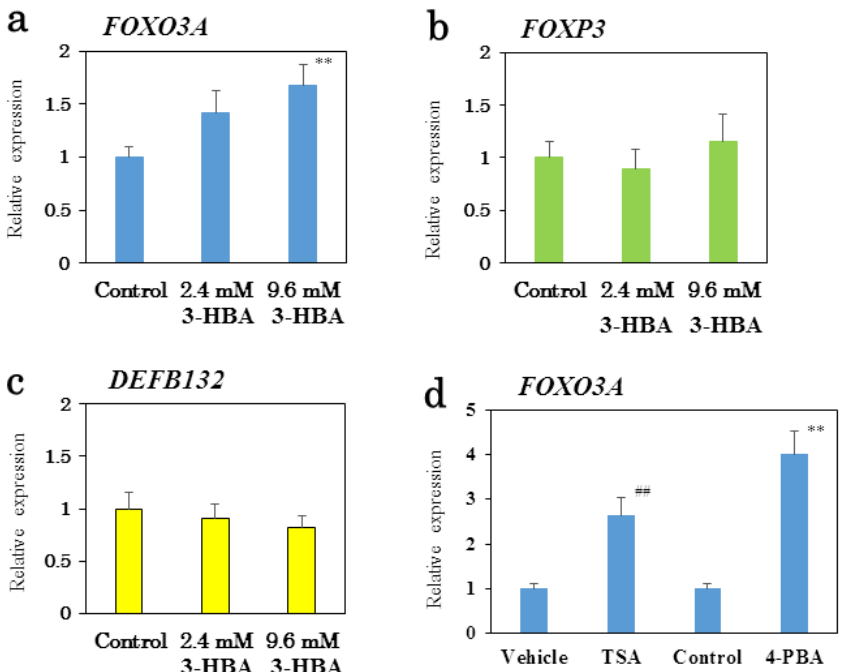

Figure 2. Effect of 3-HBA on FOXO3A mRNA expression in a human epithelial colorectal adenocarcinoma Caco-2 cell line.

qRT-PCR analysis of FOXO3A (a), FOXP3 (b), and DEFB132 (c) mRNA in Caco-2 cells treated with 3-HBA for $24 \mathrm{~h}$. (d) Effects of TSA $(3 \mu \mathrm{M})$ and 4-PBA $(10 \mathrm{mM})$ on FOXO3A mRNA expression. Results are presented as mean \pm SEM $(\mathrm{n}=10) .{ }^{* *} p<0.01$ compared with the control. ${ }^{\#} p<0.01$ compared with the vehicle $(0.1 \%$ DMSO). marker metabolite of the electron transport chain) were not affected by EF exposure. Interestingly, we found that parallel changes in 3-HBA and unsaturated fatty acids were elicited by high-strength EF exposure (4.5 kV/electrode $+4.5 \mathrm{kV} /$ electrode), but not low-strength of $\mathrm{EF}$ exposure $(2.25 \mathrm{kV} /$ electrode $+2.25 \mathrm{kV} /$ electrode $)$. Thus, it is reasonable to speculate that EF exposure partially activates fatty acid oxidation in the liver. The mean concentration of 3-HBA in human adult healthy volunteers was similar to the results of a quantitative analysis using gas chromatography $(25.3 \mu \mathrm{M})$ and Analox GM7 analyzer $(30 \mu \mathrm{M})[23,24]$. There are three types of ketone bodies: acetoacetate, acetone, and 3-HBA. Mild ketosis is a metabolic adaptation observed with caloric restriction and fasting [14,24]. Moreover, a ketogenic diet is used for epileptic seizures and food intake control via circulating blood ketones including 3-HBA [25,26]. Considerable evidences for the health benefits of physiological mild ketosis have been obtained $[14,25,26]$. Interestingly, Edwards et al. recently reported that 3-HBA extends the mean lifespan of Caenorhabditis elegans by approximately 26\% [15]. Although repetitive EF treatment was not performed in the present study, further studies should elucidate if EF-induced physiological mild ketosis affects human longevity.

Another goal of the present study was to gain insights into the genetic components affected by 3-HBA. Recently, 3-HBA was reported to be an endogenous inhibitor of HDAC1, HDAC3, and HDAC4 $[13,14]$. When considering the role of endogenous HDAC inhibitor in changes in the plasma concentrations of 3-HBA, Shimazu et al. recently reported an increase in $\mathrm{FoxO} 3 a$ gene expression induced by 3-HBA [13]. The results of our present study showed that 3-HBA $(9.6$ $\mathrm{mM}$ ) induced an approximate 1.7-fold increase in FOXO3A mRNA expression in a human epithelial colorectal adenocarcinoma Caco-2 cell line. Similar changes in FOXO3A mRNA expression were induced by the well-known HDAC inhibitors TSA and 4-PBA. Thus, we conclude that the mechanisms for 3-HBA-induced changes in FOXO3A mRNA expression may act, at least in part, through the modulation of histone acetylation. However, 3-HBA also affects $\mathrm{G}$ protein-coupled receptor 41 (GPR41) and GPR109A [27-29], raising the possibility that these receptors also serve as targets for 3-HBA during EF exposure.

In humans, Willcox et al. reported that genetic variation within the $F O X O 3 A$ gene was strongly associated with several phenotypes of healthy aging [30]. Interestingly, the Kaplan-Meier survival curves of the study population showed correlations between a high expression level of FOXO3A protein and long-term survival rate of patients with several cancers, including breast cancer and colorectal cancer [31-33]. In the future, it will be of interest to evaluate the possible effect of EF exposure on the suppression of cancer progression.

In conclusion, acute EF exposure exerted marked effects on plasma 3-HBA levels in healthy subjects, and 3-HBA induced notable effects on FOXO3A mRNA expression in a human epithelial colorectal adenocarcinoma Caco- 2 cell line. Our findings provide insights into the molecular mechanisms behind the health benefits induced by the HELP device, which may also be important for human longevity.

\section{Competing interests}

YN-Y, HH and AH are employed by Hakuju Institute for Health Science Co., Ltd., HT is employed by Acel Inc., and JA is employed by Human Metabolome Technologies Inc.. All other authors have no competing interests.

\section{Authors' contributions}

YN-Y designed and supervised the research, and wrote the 
Nakagawa-Yagi Y (2016) Effect of 3-hydroxybutyrate, an endogenous histone deacetylase inhibitor, on FOXO3A mRNA expression in human epithelial colorectal Caco-2 cells: Insight into the epigenetic mechanisms of electric field therapy

manuscript. YN-Y, HH, and $\mathrm{AH}$ performed the EF therapy and biochemical experiments. HT performed the qRT-RCR experiment. JA performed the metabolomic analysis. All authors have read and approved the final version of the manuscript.

\section{Acknowledgments}

We thank Dr. Makoto Kikuchi (Professor Emeritus, National Defense Medical College, Japan) for encouragement.

\section{References}

1. Ito F, Furuya K (1981) The effect of high voltage alternating current upon a human body the change of blood pressure, endocrine system and serum lipids (in Japanese). $J$ Jpn Sci Balneol Climatol Phys Med 45: 6-17.

2. Nawarat S, Iomsai K, Jantanam P, Kauengtip Y (1999) Effects of electrical Healthtron on curing of non-communicable diseases: Case study of Banlad hospital Petchaburi province (in Thai). Region 4 Medical J 18: 139-149.

3. Ito F (2000) The role of electric field therapeutic device (Healthtron) in the therapy of acute low back pain (in Japanese). J Jpn Sci Balneol Climatol Phys Med 63: 127 -137.

4. Siripanichgon K, Otrakul A, Suparp J, Sirikulchayanonta C, Charupoonphol P (2000) Clinical observation of Healthtron therapy (in Thai). J Public Health (Bangkok) 30: 19-29.

5. Sirikulchayanonta C, Siripanichgon K, Otrakul A, Suparp J, Charupoonphol P (2001) The effect of Healthtron on serum lipid levels among the middle-aged: Preliminary report. J Public Health (Bangkok) 31: 63-70.

6. Chen R, Wang C (2002) Observation of therapeutic effect on insomnia and headaches by high-potential treatment (in Chinese). Modern Medical Science Apparatus and Application 14: 5-6.

7. Ito F, Ohsaki K, Takahashi K, Hara H (2005) The effects of electric field therapeutic device (Healthtron) on the stiffness in the neck and shoulder area - changes in subjective symptoms, blood circulation and the autonomic nervous system (in Japanese). JJpn Sci Balneol Climatol Phys Med 68: 110-121.

8. Shinba T, Takahashi K, Kanetaka S, Nedachi T, Yamaneki M, et al. (2012) A pilot study on electric field therapy for chronic pain with no obvious underlying diseases (in Japanese). Soc Integrative Med Jpn 5: 68-72.

9. Mitani Y, Matsugi A, Okano H, Nedachi T, Hara H (2015) Effect of exposure to a high-voltage alternating current electric field on muscle extensibility. JJpn Sci Balneol Climatol Phys Med 78: 244-252.

10. Nakagawa-Yagi Y, Hara H, Fujimori T, Yamaguchi T, Midorikawa A, et al. (2014) Non-targeted human plasma metabolomics reveals the changes in oleoylethanolamide, a lipid-derived signaling molecule, by acute exposure of electric field. Integr Mol Med 1: 29-37.

11. Nakagawa-Yagi Y, Hara H, Yoshida Y, Midorikawa A, Hara A (2015) Discovery of a novel effect of electric field exposure on human plasma beta-endorphin and interleukin-12 levels: Insight into mechanisms of pain alleviation and defense against infection by electric field therapy. Integr Mol Med 2: 200-204.

12. Nakagawa-Yagi Y, Hara H, Nakagawa F, Sato M, Hara A (2016) Acute exposure to an electric field induces changes in human plasma 9-HODE, 13-HODE, and immunoreactive substance P levels: Insight into the molecular mechanisms of electric field therapy. Integr Mol Med 3: 600-605.

13. Shimazu T, Hirschey MD, Newman J, He W, Shirakawa K, et al. (2013) Suppression of oxidative stress by $\hat{\mathrm{I}}^{2}$-hydroxybutyrate, an endogenous histone deacetylase inhibitor. Science 339: 211-214. [Crossref]

14. Newman JC, Verdin E (2014) Ketone bodies as signaling metabolites. Trends Endocrinol Metab 25: 42-52. [Crossref]

15. Edwards C, Canfield J2, Copes N2, Rehan M2, Lipps D, et al. (2014) D-betahydroxybutyrate extends lifespan in C. elegans. Aging (Albany NY) 6: 621-644. [Crossref]

16. Kang HL, Benzer S, Min KT (2002) Life extension in Drosophila by feeding a drug. Proc Natl Acad Sci U S A 99: 838-843. [Crossref]

17. Tao D, Lu J, Sun H, Zhao YM, Yuan ZG, et al. (2004) Trichostatin A extends the lifespan of Drosophila melanogaster by elevating hsp22 expression. Acta Biochim Biophys Sin (Shanghai) 36: 618-622. [Crossref]

18. McColl G, Killilea DW, Hubbard AE, Vantipalli MC, Melov S, et al. (2008)
Pharmacogenetic analysis of lithium-induced delayed aging in Caenorhabditis elegans. J Biol Chem 283: 350-357. [Crossref]

19. Vaiserman AM, Kolyada AK, Koshel NM, Simonenko AV, Pasyukova EG (2012) Effect of the histone deacetylase inhibitor sodium butyrate on viability and life span in Drosophila melanogaster (in Russian). Uspekhi Gerontologii 25: 126-131.

20. Nakagawa-Yagi Y, Sato Y, Matsumoto E, Nakatsuka S, Sakaki T, et al. (2012) Pharmacological modulation of histone demethylase activity by a small molecule isolated from subcritical water extracts of Sasa senanensis leaves prolongs the lifespan of Drosophila melanogaster. BMC Complement Altern Med 12: 101

21. Nakagawa-Yagi Y, Sato Y, Muramatsu Y, Hara T, Aigaki T (2013) Effect of a red winederived polyphenol protocatechuic acid on the lifespan of Drosophila melanogaster (in Japanese). Food Function 11: 9-13.

22. Kim YS, Seo HW, Lee MH, Kim DK, Jeon H, et al. (2014) Protocatechuic acid extends lifespan and increases stress resistance in Caenorhabditis elegans. Arch Pharm Res 37: 245-252. [Crossref]

23. Kimura M, Kobayashi K, Matsuoka A, Hayashi K, Kimura Y (1985) Head-space gaschromatographic determination of 3-hydroxybutyrate in plasma after enzyme reactions, and the relationship among the three ketone bodies. Clin Chem 31: 596-598.

24. Pan JW, Rothman TL, Behar KL, Stein DT, Hetherington HP (2000) Human brain betahydroxybutyrate and lactate increase in fasting-induced ketosis. J Cereb Blood Flow Metab 20: 1502-1507. [Crossref]

25. Bough KJ, Rho JM (2007) Anticonvulsant mechanisms of the ketogenic diet. Epilepsia 48: 43-58. [Crossref]

26. Paoli A, Bosco G, Camporesi EM2, Mangar D3 (2015) Ketosis, ketogenic diet and food intake control: a complex relationship. Front Psychol 6: 27. [Crossref]

27. Kimura I, Inoue D, Maeda T, Hara T, Ichimura A, et al. (2011) Short-chain fatty acids and ketones directly regulate sympathetic nervous system via $G$ protein-coupled receptor 41 (GPR41). Proc Natl Acod Sci USA 108: 8030-8035. [Crossref]

28. Won YJ, Lu VB, Puhl HL 3rd, Ikeda SR (2013) $\hat{I}^{2}$-Hydroxybutyrate modulates N-type calcium channels in rat sympathetic neurons by acting as an agonist for the G-proteincoupled receptor FFA3. J Neurosci 33: 19314-19325. [Crossref]

29. Singh N, Gurav A, Sivaprakasam S, Brady E, Padia R, et al. (2014) Activation of Gpr109a, receptor for niacin and the commensal metabolite butyrate, suppresses colonic inflammation and carcinogenesis. Immunity 40: 128-139. [Crossref]

30. Willcox BJ, Donlon TA, He Q, Chen R, Grove JS, et al. (2008) FOXO3A genotype is strongly associated with human longevity. Proc Natl Acad Sci U S A 105: 13987-13992. [Crossref]

31. Jiang Y, Zou L, Lu WQ, Zhang Y, Shen AG (2013) Foxo3a expression is a prognostic marker in breast cancer. PLoS One 8: e70746. [Crossref]

32. Bullock MD, Bruce A, Sreekumar R, Curtis N, Cheung T, et al. (2013) FOXO3 expression during colorectal cancer progression: biomarker potential reflects a tumor suppressor role. Br J Cancer 109: 387-394.

33. Taylor S, Lam M, Pararasa C, Brown JE, Carmichael AR, et al. (2015) Evaluating the evidence for targeting FOXO3a in breast cancer: a systematic review. Cancer Cell Int 15: 1. [Crossref]

Copyright: (C2016 Nakagawa-Yagi Y. This is an open-access article distributed under the terms of the Creative Commons Attribution License, which permits unrestricted use, distribution, and reproduction in any medium, provided the original author and source are credited. 